University of Maryland Francis King Carey School of Law

DigitalCommons@UM Carey Law

3-1-1988

\title{
Baby $M$, the Surrogacy Contract, and the Health Care Professional: Unanswered Questions
}

Karen H. Rothenberg

University of Maryland School of Law, krothenberg@law.umaryland.edu

Follow this and additional works at: https://digitalcommons.law.umaryland.edu/fac_pubs

Part of the Health Law and Policy Commons

\section{Digital Commons Citation}

Rothenberg, Karen H., "Baby M, the Surrogacy Contract, and the Health Care Professional: Unanswered Questions" (1988). Faculty Scholarship. 150.

https://digitalcommons.law.umaryland.edu/fac_pubs/150

This Article is brought to you for free and open access by the Francis King Carey School of Law Faculty at DigitalCommons@UM Carey Law. It has been accepted for inclusion in Faculty Scholarship by an authorized administrator of DigitalCommons@UM Carey Law. For more information, please contact smccarty@law.umaryland.edu. 


\title{
Case Review Essay
}

\section{Baby M, the Surrogacy Contract, and the Health Care Professional: Unanswered Questions}

\author{
Karen H. Rothenberg
}

The Baby $M$ case ${ }^{2}$ has forced us to take sides in the public debate over surrogate motherhood. Last year, advocates of this form of noncoital reproduction praised the New Jersey trial court ${ }^{2}$ for supporting the freedom to contract for such "womb renting" services, while critics warned that enforcement of such surrogacy contracts would condone the sale of babies and the exploitation of women as baby factories. In its unanimous opinion, the New Jersey Supreme Court sided with the critics. ${ }^{3}$ Based on New Jersey's adoption law and public policy, the court refused to enforce the contract that provided money to a surrogate mother in return for her agreeing to be artificially inseminated with the semen of another woman's husband, to conceive a child, to carry it to term, and to relinquish her parental rights and surrender her child to the natural father and his wife, regardless of the child's best interests. The court believed that its "declaration that this surrogacy contract is unenforceable and illegal is sufficient to deter similar agreements." 4

The court was particularly offended by the payment of money in exchange for bearing and relinquishing a baby. "There are," it said, "in a civilized society, some things that money cannot buy."5 Payment of money to the surrogate was "illegal, perhaps criminal, and degrading to women." The court found "no offense" to present laws where a woman serves as a surrogate without payment, provided she is not subject to a binding agreement to surrender her child. ${ }^{7}$ Nor did it preclude the legislature from altering the statutory scheme to permit surrogacy contracts, within constitutional limits-limits that the court did not define and that are not easily definable.

The court concluded its ninetyfive-page opinion with a prediction-and perhaps a hope for the future:

Legislative consideration of surrogacy may also provide the opportunity to begin to focus on the overall implications of the new reproductive biotechnology.... The problem can be addressed only when society decides what its value and objectives are in this troubling, yet promising, area. ${ }^{8}$

Perhaps this is why legislatures have had so much trouble passing laws in this area. Although bills have been introduced in the majority of states, as well as Congress, to either ban or regulate surrogacy, most have died in committee. The Baby $M$ decision, however, has stimulated debate and has influenced the direction of recent legislation. New Jersey's Supreme Court is well respected nationwide for its leadership in analyzing complex ethical issues. What impact will its analysis have on those states where surrogacy contracts will continue to be written in a legal wasteland? For couples desperate to have'a child, for women desperate for money, and for brokers desperate to get rich, the risks may still be worth taking.

But what about the role of the health professional in the surrogacy process? What issues have been clarified by the Baby $M$ decision and the surrogacy contract? What questions still remain unanswered? And, what new questions have been raised?

To put such questions in some context, it is worth noting that nineteen amicus briefs were filed with the New Jersey Supreme Court in this case, expressing various interests and views on surrogacy. In fact, the court specifically acknowledged that many of them were helpful in resolving the issues. ${ }^{9}$ Yet not one 
brief was filed on behalf of a healthprofessional association. One can only speculate that such groups did not view the Baby $M$ case as a relevant case of nationwide importance and/or that they had not officially considered their positions on surrogacy. Not one of the major mental health associations, including the American Psychological Association and the American Psychiatric Association, had officially considered the issue. In fact, very little evidence has appeared in any of the scientific journals on surrogacy. Either the Baby $M$ decision will increase demand for evidence on the effects of surrogacy or it will dry up interest. Or, perhaps, the issue is just too controversial for health-professional groups struggling for consensus.

Yet as early as 1983 , the Judicial Council of the American Medical Association (AMA) and the Executive Board of the American College of Obstetrics and Gynecology (ACOG) issued policy statements on surrogacy. ${ }^{10}$ As late as September 1987 , the AMA affirmed its opposition to surrogacy to the Drafting Committee on the "Status of Children of the New Biology" of the National Conference of Commissioners on Uniform State Laws: "Surrogate parent contracts do not represent a satisfactory reproductive alternative for those who wish to become parents." ${ }^{11}$ The AMA opposed state legislation to sanction such arrangements.

Although ACOG is reevaluating its position in light of the Baby $M$ decision, its present ethical guidelines do not condemn the practice. They do, however, express "significant reservations about this approach to parenthood." Of particular concern is the difficulty of differentiating between payments for the service of carrying the child and the payment for the child itself-clearly a practice that is "illegal and morally objectionable." ACOG also warns against investing in surrogacy businesses or accepting money for recruiting or referring potential surrogates. The physician "should not participate in a surrogate program where the financial arrangements are likely to exploit any of the parties." Yet in the end, the decision about whether to participate in a surrogacy arrangement is left up to the physician. Such a decision should be made only after the physician has weighed all the "legal, psychological, societal, medical and ethical aspects." 12

In 1986 , the Ethics Committee of the American Fertility Society issued its report on "Ethical Considerations of the New Reproductive Technologies." "3 The committee concluded that if surrogate motherhood is pursued, it should be as a "clinical experiment." ${ }^{4}$ Unfortunately, this experiment will not answer the current concerns about the enforceability of the surrogate contract and the custody of the child. In fact, a few members of the committee questioned whether, given the small number of couples involved, it was likely that significant research would be performed. Others would not endorse a procedure that was so highly controversial and whose risk-benefit ratio did not justify support. ${ }^{15}$

In spite of the fact that these groups did not play an active role in the Baby $M$ appeal, the court's decision and its potential impact on the surrogacy contract continue to raise a number of unanswered questions for the health care professional. Will participation in such arrangements carry a taint of immorality-and perhaps a threat of criminality? Will exposure to professional liability increase with more demand for screening, counseling, and evaluation? Will future regulation place health care professionals in the role of "guarantors" of the agreement? At various stages of the surrogacy process, the professional is faced with a number of complex questions, many with no answers. By examining the Baby $M$ case and its surrogacy con- tract, this article highlights these unanswered questions and the implications for health care professionals.

\section{The "Perhaps Criminal" Role}

The Baby $M$ case was a dispute about a contract and the custody of Baby M, not about criminal liability. Yet the court stated, albeit in dictum, that the surrogate arrangement was "perhaps criminal" under New Jersey law. ${ }^{16}$ What are the implications of this confusing phrase?

New Jersey law prohibits the use of money in connection with adoptions. Violation of this "baby selling" law is a high misdemeanor, a third-degree crime carrying a three-to five-year prison term. ${ }^{17} \mathrm{Ex}$ cepted are fees of an approved agency and payment or reimbursement for medical, hospital, or related expenses incurred in connection with the birth of the child. Although the Baby $M$ contract provided that the fees paid were for services and expenses, the court concluded that the parties knew it was nothing other than a privateplacement adoption for money. The contract provided for "the sale of a child, or at the very least, the sale of a mother's right to her child, the only mitigating factor being that one of the purchasers is the father." 18

The court concluded that the evils that prompted the prohibition against the payment of money in connection with adoption are present in the surrogacy arrangement. In both cases, "the essential evil is the same, taking advantage of the woman's circumstances (the unwanted pregnancy or the need for money) in order to take away the child." In the court's view, it was the middleman-the surrogate brokermotivated by the profit motive, who promotes the sale. The profit motive-and not the best interests of the parties- " predominates, permeates, and ultimately governs the transaction." 19

The court never mentioned the 
role of the health professional in the context of the baby-selling prohibition. Yet the taint of immorality and possible criminality permeates the court's analysis. To date, twentyfour states have enacted laws prohibiting baby-selling. ${ }^{20}$ If babyselling laws are interpreted to cover the surrogacy arrangement, they may be interpreted broadly enough to subject a health care professional to criminal liability for his or her participation. ${ }^{21}$ Moreover, since Baby $M$ was decided, at least five states have passed statutes restricting commercial surrogacy. ${ }^{22}$ The Baby M contract provided for artificial insemination, for a fee, by a physician. The contract provided for evaluation, for a fee, by a psychiatrist. The contract provided for the inseminating physician, for a fee, to make judgments about genetic testing. Health professionals legitimized the "medical" aspects of the process. By their actions, they sanctioned the deal. Without the involvement of the health care professionals, would the surrogate arrangement be as profitable? Would it continue to be characterized as a reproductive "technology"? Does the participation of the health care professional-although not critical to the deal-contribute to its success as a "medical" solution to infertility? Unless the health care professional also serves as a broker, referral service, and/or owner of a surrogacy agency, it is highly unlikely that there would be fair notice under most existing state laws to be criminally liable. ${ }^{23}$ Yet the charge of "aiding and abetting" a crime would not be out of the question.

A more realistic fear for the health care professional may be the impact of characterizing the surrogacy process as immoral, illegal, and "perhaps criminal." Will professionals want to take the risk? Will health professionals disassociate themselves from surrogacy? At what price? Criminalization of surrogacy may drive the business underground, without sufficient quality control. In the meantime, without further legislative clarification, the hint of potential criminality should at least cause those professionals participating in a surrogacy contract to analyze their role throughout the process. In the end, they may be faced with even more unanswered questions.

\section{Pre-Insemination: Evaluation, Counseling, and "Informed Consent"}

Contrary to all the protection provided for counseling prior to termination of parental rights, the court found that the surrogacy contract did not provide for "counseling, independent or otherwise, of the natural mother, no evaluation, no warning." ${ }^{24}$ The lack of counseling and evaluation reinforced the court's determination to void the agreement.

Apparently the only psychological evaluation performed on Ms. Whitehead took place almost two years prior to her agreement with Mr. Stern. According to the trial court, Ms. Whitehead received a "psychological evaluation to determine her suitability as a potential surrogate candidate" at the Infertility Center of New York (ICNY). Although the "examiner" thought it important to explore her ability to relinquish the child in more depth, she was recommended as an appropriate candidate. "It was this fact of prior evaluation that the Sterns relied on." 25 According to the trial court, Ms. Whitehead also testified that she received two counseling sessions at ICNY, a point ignored by the New Jersey Supreme Court.

The Supreme Court raised a number of concerns about the role of evaluation and counseling. It questioned whether the evaluation served anyone but ICNY. ${ }^{26}$ Nothing in the record stated that the evaluation was for the surrogate's benefit. To the contrary: Ms. Whitehead testified that all she was told was that "she had passed." 27 The Sterns never asked to see the evaluation. They assumed that ICNY had made an evaluation and "had concluded that there was no danger that the surrogate would change her mind." 28

The court stressed the fact that a psychologist had warned that Ms. Whitehead demonstrated certain traits that "might make surrender of the child difficult and that there should be further inquiry." The court speculated that to inquire further may have jeopardized the deal, believing that the "profit motive got the better" of ICNY. ${ }^{29}$

The court ignored the provision in the contract that specifically stated that a "psychiatric" evaluation was to be arranged for both Mr. and Ms. Whitehead, to be paid for by Mr. Stern, and that the Whiteheads were to sign a release permitting dissemination of the evaluation report to ICNY or the Sterns..$^{3^{\circ}} \mathrm{Did}$ this evaluation ever take place as provided in the contract? If so, what were the results? Is this the evaluation the Supreme Court was describing? Or did the Sterns waive this contract provision and rely on the evaluation done almost two years earlier by a clinical psychologist on contract with ICNY?

The facts are not clear from the record. What is clear is that the court envisioned a process of both evaluation and counseling. A more in-depth evaluation would have focused on the likelihood of Ms. Whitehead changing her mind, while extensive counseling would have alerted her to the potential impact of relinquishing her child.

Should the mental health professional be in a position to guarantee that a mother won't change her mind or that her consent is voluntary? Is this an assessment that the court would agree was impossible until after birth? ${ }^{31}$ How would the professional make such assessments? What traits, in fact, should the professional look for-stability, pecuniary motives, detachment, 
sensitivity $?^{32}$ Will the surrogate with a detached personality have the easiest time relinquishing, but also be most unconcerned during the pregnancy? Perhaps the most sensitive person would feel a sense of duty to the infertile couple and find it easiest to relinquish a child. What was it about Ms. Whitehead's personality that caused doubt? Do psychologists on contract with a surrogacy agency ever recommend that a candidate not be approved? If the initial evaluation raises questions, do you stop there? Or should the mental health professional re-evaluate following counseling? Should counseling include surrogate "support groups" in which the surrogate candidate can minimize her feelings of doubt? And how often should evaluations take place? For example, would the Baby $M$ court require evaluation and counseling each month prior to insemination:

The court speculated that if either the Sterns or Ms. Whitehead had been told the details of the evaluation, the agreement would never have been made. ${ }^{33}$ The evaluation, if shared, might have warned both parties and put them on notice. The court pointed out that both parties suffered severe emotional distress, which could have been avoided with proper evaluation and full disclosure and counseling. ${ }^{34}$ Yet the contract between Mr. Stern and ICNY made it quite clear that ICNY would "not guarantee or warrant" that the surrogate would comply, including, but not limited to, her "refusal to surrender custody of the child upon birth." 35 Mr. Stern also specifically released ICNY from any liability "related to or arising from any agreement or understanding between himself and a 'surrogate mother' located through the services of ICNY." ${ }^{6}$

The court questioned whether, even with sufficient evaluation and counseling, a surrogate could ever grant "informed consent" to the terms of the surrogate contract. Tra- ditionally, informed consent requires that the patient be told of the risks and benefits of the trearment options. For the trial court, informed consent was defined as a "concept used in the trial of medical malpractice cases." The trial court rejected Ms. Whitehead's argument that until she "felt the emotion of birth and sensed the child, she could not give informed consent at the time she signed the contract." To accept this expanded concept of informed consent would put "all contracts in limbo." 37

On the contrary, the Supreme Court was concerned not so much with informed consent to a medical procedure (the insemination procedure is a simple, non-material risk) but, rather, with the consent to relinquish the baby at the time of signing the contract. The court embraced a broad definition of informed consent that is somewhat foreign to contract law. A standard contract requires only that both parties are competent at the time the agreement is made. In fact, the contract stated that both parties "freely and voluntarily" signed the agreement. ${ }^{38}$

Perhaps the court deemed it "impossible" and/or "impracticable" for a natural mother to consent to relinquish her child until a reasonable time after birth. Without any scientific evidence cited, the court took judicial notice that the "natural mother is irrevocably committed before she knows the strength of her bond with her child." In the "most important sense" her decision is "uninformed."39

As a practical matter, what should the consent process include? Is a health care professional qualified to disclose the medical, psychological, legal, and financial risks and benefits of the surrogate contract? How certain is any of this information? The medical risks associated with insemination and pregnancy are currently to be disclosed. But what about the long-term psycho- logical risks to the parties, their families, and the child? Furthermore, the uncertainty of the legal and financial issues clouds consent even more. At best, "informed consent" will be a warning to all potential parties about all foreseeable risks.

Some states may attempt to regulate surrogacy by delineating standards for screening, evaluation, counseling, and informed consent prior to the signing of a contract. For example, recent proposals require the surrogate and the natural father to submit to physical and genetic screening. The surrogate may also be required to undergo psychological evaluation to determine whether any medical disability would prevent her from abiding by the terms of the contract. A few proposals require that a licensed marriage counselor, psychologist, or psychiatrist certify that "the consequences and responsibilities of surrogate parenthood" were explained to the natural father and his wife, that "the surrogate had the capacity to consent," and that "the potential psychological consequence of her consent" had been discussed. ${ }^{\circ}$ Proposals in Connecticut and Hawaii, for example, prohibit insemination unless the "physician is professionally satisfied with the mental and physical suitability of the surrogate and the natural father." 4

Such requirements seem to put the health care professional in the position of "guarantor" of the surrogacy process. Will professionals have to guarantee or warrant that the mother will not change her mind, that the medical and genetic makeup of all the parties proves acceptable, that the psychological evaluation assures no problems, and that the parties have been warned of all risks?

Such attempts at regulation may transform surrogacy from a commercial enterprise to a medically controlled reproductive choice. With more involvement of health care professionals, will the surro- 
gacy process be legitimized? Is this a role that health care professionals want to accept? If so, who will monitor their compliance with the standards? Will such a role increase professional liability? What will the standard of care be for assessing their role in the pre-conception deal? And what if the deal falls apart? The legal and ethical risks should force health care professionals to become more involved in evaluating proposals for surrogacy regulation.

\section{Insemination}

In the typical surrogacy arrangement, the surrogate candidate is artificially inseminated with the semen of another woman's husband. This process does not require any complex reproductive technology. A physician's expertise is not essential. In fact, artificial insemination can be done at home with a turkey baster. State laws regulate artificial insemination to varying degrees. ${ }^{42}$ In a few states it is a criminal offense for anyone other than a licensed physician to perform artificial insemination. ${ }^{43}$

The Baby M contract specifically provided that the surrogate would be "artificially inseminated with the semen of the natural father by a physician." 44 Although contracts may vary as to the role of screening and evaluation at the pre-conception stage, it is clear that the physician takes a role in beginning the conception process. Prior to each attempt, the sperm donor and the surrogate should be screened for sexually transmitted diseases. As in the Baby $M$ case, insemination may be tried a number of times before conception occurs.

The health care professional's involvement is necessary for the surrogacy contract to proceed (assuming the parties reject the at-home turkey-baster method and sexual intercourse). The physician benefits financially from this process. He or she is paid a fee for this service and may have contracted with the surro- gate agency to inseminate and screen all surrogates. Does the inseminating physician also have a physicianpatient relationship with the surrogate and the natural father, or is this strictly a business relationship with the surrogacy agency?

\section{Prenatal Care}

Once insemination is successful and conception occurs, the contract may provide for a continuing role for the inseminating physician. How does the surrogacy contract shape medical decision-making, and how does it affect the health care professional?

The Baby $M$ contract set out a number of specific terms related to prenatal care. First, Ms. Whitehead agreed not to abort unless, "in the professional medical opinion of the inseminating physician" it was necessary for her "physical health" or the child had been found to be "physiologically abnormal." Furthermore, "upon the request" of the inseminating physician, she would agree to "undergo amniocentesis or similar tests to detect genetic and congenital defects." $4 \bar{s}$

These provisions place all the decision-making authority with the inseminating physician. What relationship does this physician have to the surrogate? What role does her independent obstetrician have in her care? To what extent does the inseminating physician know of her physical health-and what about her emotional health? Does the inseminating physician take orders from the surrogate agency and/or those who pay his or her fee? Will the profit motive "get the best of" the physician under these circumstances? In spite of the contract, it was Mr. Stern's wife, a physician herself, who insisted that Ms. Whitehead undergo amniocentesis. The actual role of any other physician is unknown from the record. ${ }^{4}$

The Baby $M$ contract provided that the surrogate would receive no compensation if she miscarried prior to the fifth month. ${ }^{47}$ What if an ordered amniocentesis had brought about a miscarriage? Who would have the cause of action against which physician? If the baby had been stillborn subsequent to the fourth month, Ms. Whitehead would have received only $\$_{1}$, ooo..$^{8}$ Would the surrogate and the natural father have a cause of action against the physician for negligence if they could prove the physician caused the stillbirth? Could the mother sue for the difference of the $\$ 9,000$ and her expenses? Could the father sue for all his expenses? Obviously, if the contract is unenforceable, the contract remedy would not be available; but what about a potential negligence case? Could all parties establish a duty of the professional to provide a perfect, final "product"?

The Baby $M$ contract did provide that if prenatal testing revealed any defects, the surrogate, "upon demand" of Mr. Stern, would abort the fetus or forfeit the money. ${ }^{49}$ Even the trial court determined that this provision was clearly void and unenforceable..$^{\circ}$ Relying on Roe $v$. Wade,,$^{5}$ it found " $[$ t] $]$ hat only the woman has the constitutionally protected right to determine the manner in which her body and person shall be used." $5^{2}$

In another contract provision ignored by both courts, the surrogate would agree "to adhere to all medical instructions given to her by the inseminating physician as well as her independent obstetrician." 53 But what if there had been a conflict between the physicians? Was Ms. Whitehead the patient of both physicians?54 Did she have a relationship only with her independent physician? And if so, why should the inseminating physician have a role in her prenatal care? Because the contract said so? And which physician's instructions was she to consider?

The contract further set out that Ms. Whitehead was not to "smoke cigarettes, drink alcoholic bever- 
ages, use illegal drugs, or take nonprescription medications or prescribed medications without written consent from her physician." 55 Which physician was this? What if she had told her "independent" physician that she had been drinking or smoking cigarettes in violation of the contract? And what if she had missed a scheduled appointment as set out in the contract? Was her physician supposed to write these facts in the chart because they are medically relevant, or should he or she not put such facts in her record because they violate the contract? Should the physician report compliance or lack thereof to anyone else? Should a copy of the contract and its terms be placed in the surrogate's medical record? What if she gives the contract to her physician or the surrogate agency sends it to him or her? Should the physician-whose interest is in protecting the welfare of the patient and the fetus ${ }^{6}$ ignore the contract and act as if it doesn't exist:

Since her "independent obstetrician" is not part of the business deal, maybe the surrogate will not tell this physician about the contract. Does she have a reason to "deceive" her doctor? Would the doctor and the staff treat her differently? Her physician might be better off not knowing about the terms of the contract and its "rules" on medical decision-making. It certainly would make the situation less complicated. Yet this information may be relevant to her prenatal care. What if her blood pressure began to rise? Such a reaction could be due to the ambivalence she feels about giving up the child-or maybe she fears that if she refuses to give up the child she will be sued. And what about the stress that her husband may feel about her pregnancy? Maybe her children are pressuring her not to give up the baby. Shouldn't her physician have this information? The physician may believe that the stress of the arrangement is causing psy- chological and potential physical harm to the mother and the fetus. With this information, what should the physician do? Should he or she order counseling to reduce the mother's feelings of stress and bonding, or should counseling be directed toward validating her "natural" feelings about not wanting to relinquish the child-the possible position of the Baby $M$ court?

What benefits the surrogate medically may not benefit her financially if she refuses to relinquish the baby. Is this a risk the surrogate assumes? Should the natural father pay all these expenses as foreseeable under the arrangement, whether or not the mother decides to keep the baby? The Baby $M$ contract provided that the natural father should pay all expenses "not covered or allowed by her present health and major medical insurance, including all extraordinary medical expenses and all reasonabie expenses for treatment of any emotional or mental conditions or problems related to said pregnancy." 57 What is deemed "reasonable" expenses for "emotional problems"? Who makes this determination? If counseling results in the surrogate's decision not to relinquish the child, is the surrogate financially liable? If the natural father pays, does he have a role in directing the medical and psychological care provided? In the end, it may be the physician who ultimately determines the "success" of the surrogacy deal for all the parties. The health care professional will be forced to balance the patient's needs with financial, legal, and ethical uncertainties.

\section{The Birth}

When Baby $M$ was born, no one on the hospital staff appeared to know that the baby was the "product" of a surrogate contract. The court described the following scene:

Not wishing anyone at the hos- pital to be aware of the surrogacy arrangement, $\mathrm{Mr}$. and Mrs. Whitehead appeared to all the proud parents of a healthy female child. ... In accordance with Mrs. Whitehead's request, the Sterns visited the hospital unobtrusively to see the newborn child..$^{8}$

Contrary to a specific provision in the contract, ${ }^{59} \mathrm{Ms}$. Whitehead named the child Sara Elizabeth Whitehead on the birth certificate and Mr. Whitehead was named as the father. ${ }^{60}$ In short, the hospital staff had been deceived.

But what if the facts had been different? What if the hospital staff had known of the arrangement and the mother appeared to have a conflict about relinquishing the baby? Should the physician or nurse have let the mother hold or nurse the baby? Such action might encourage even more bonding or attachmentsomething not agreed to in the contract, but standard practice. In fact, some proposed surrogate contracts provide that the surrogate not breast-feed following the birth. And who would take the baby home at the time of discharge? Without a court order or formal proof of relinquishment for adoption, most hospitals would release a child only to the natural mother. Hospital policy and fear of liability would not allow otherwise.

Furthermore, what if the baby had not been born healthy? Which parent would be granting consentor denying it-for immediate medical care? If Baby $M$ had needed medical care, the hospital staff would have sought the consent from Mr. and Ms. Whitehead. They did not know that the natural father was Mr. Stern. The Whiteheads appeared to be the legal guardians at the time of birth. But what if there had been a conflict about medical care? Or what if the baby had been deformed and no one wanted to take responsibility? The physician could 
have been forced-as one doctor was in a 1983 case-to get a court order to treat the medical problems of a child born with microcephaly. ${ }^{6}{ }^{1}$ The disappointment of having a less than perfect child is hard for any parent to accept. It is also one of the most difficult problems for the physician to work out with parents. In fact, hospital ethics committees have been formed to assist the medical staff and family make complex ethical and medical decisions about treatment for severely defective newborns. To further complicate matters, the physician and the hospital staff would have to figure out which possible parent speaks on behalf of the best interests of the child.

There have been a few failed attempts to regulate decision-making at the time a surrogate mother gives birth. Some proposals would give authority to the natural mother through birth and immediately thereafter, ${ }^{62}$ while others would shift authority at the time of viability to the natural father and his wife. ${ }^{63}$ For the physician and the hospital staff, it seems safest to place these decisions with the natural mother, assuming that she is acting in the best interests of the child. But what if the natural mother then relinquishes the less than perfect baby to the natural father, pursuant to the contract? He may not want the "damaged goods" either; the child could be abandoned by all parties. ${ }^{6}$ In a recent case reported in the New England Journal of Medicine, a surrogate mother passed HIV infection to the fetus. Neither the surrogate nor the natural father wanted custody of the infant. ${ }^{65}$

Even if a natural father is granted custody, he may not have had a role in the medical decisionmaking process at birth. The physician may not have known of the surrogacy arrangement. Faced with significant medical and related expenses for his defective child, the father, having had no input into the medical decisions involved, may look for a "deep pocket" to sue. Both the health care professional and the hospital will face an increasing risk of liability from all parties.

\section{Conclusion}

Baby $M$ was not a case about health care professionals. Yet examination of the surrogacy contract reveals the importance of the health care professional as a player in the process. From the initial evaluation of the surrogate mother through the birth of the contracted-for child, health care professionals face a number of complex legal and ethical questions. Many of these questions have no answers. If state legislatures begin to regulate surrogacy, health care professionals will be expected to assume an increasing role as "guarantors" in the process. This is a role that the health care professional should not accept without a clear recognition of the inevitable conflicts.

\section{References}

1. In re Baby M, 14 FLR 2007 (N.J. Sup. Ct. 1988).

2. 13 FLR 2001, 217 N.J. Super. 313 (1987).

3. Nevertheless, the Supreme Court did defer to the trial court in granting custody to William Stern, the natural father, as serving the best interests of Baby M. It voided the adoption by Elizabeth Stern, however, and restored the parental rights of the natural mother, Mary Beth Whitehead, including her right to visitation.
4. 14 FLR at 2022.
5. Id.: 2018 .
6. Id.: 2008 , emphasis added.
7. Id.
8. 14 FLR at 2027.
g. Id.: 2011.
10. See ACOG Statement of Policy, "Ethical Issues in Surrogate Motherhood," May 1983; American Medical Association, "Report of the Judicial Council, Report B" (I-84) and related documentation; American Fertility Society, "Surrogate Mothers" (Chapter 25 of Ethical Considerations of the New Reproductive Technologies), Fertility and Sterility, $4^{6}$ (1986): Supp. 1, $62 \mathrm{~S}-68 \mathrm{~S}$.

11. See Letter from James H. Sam- mons, M.D., AMA executive vice president, to Robert Robinson, chairman, Drafting Committee on "Status of Children of the New Biology" (Sept. 22, $1987)$.

12. ACOG Statement of Policy, supra note 10 .

13. See American Fertility Society, "Surrogate Mothers," supra note 10.

14. Id.: $67 \mathrm{~S}$.

I5. Id.: $68 \mathrm{~S}$

16. 14 FLR at 2008.

17. N.J.S.A. 9:3-54. See 14 FLR at 2012 , note 4 .

18. 14 FLR at 2017.

19. Id.

2o. See Katz, "Surrogate Motherhood and the Baby-Selling Laws," Columbia Journal of Law \& Social Problems, (1986): 1, 8-9, n. 34 (lists state statutes prohibiting payment for adoption).

21. Id. See also Cohen and Friend, "Legal and Ethical Implications of Surrogate Mother Contracts," Clinics in Perinatology, 14 (1987): 281, 284 .

22. See Larry Gostin, "Introduction," in this issue, for a discussion of these statutes.

23. The president of Surrogate Parenting Associates, the subject of a protracted legal battle in Kentucky, was a physician who was "paid a fee by the biological father for selection and artificial insemination of the surrogate mother." See Surrogate Parenting Associates, Inc. v. Commonwealth ex rel. Armstrong, 704 S.W.2d 209, 211 (Kentucky 1986); see also Karnezis, "Criminal Liability of One Arranging for Adoption of Child Through Other Than Licensed Child Placement Agency ("Baby Broker Acts');"' 3 ALR 4th 468 ; Montana Dept. of Social \& Rehab. Services v. Angel, 577 P.2d 1223 (Montana 1978) (physician enjoined from placing children for adoption without a license, but court did not discuss criminal liability for baby-selling).

24. 14 FLR at 2016.

25. 13 FLR at 2008.

26. 14 FLR at 2016.

27. Id.: 2017 .

28. Id.: 2016 .

29. Id.: 2017 .

3o. Id.: 2028, App. A, "Surrogate Parenting Agreement," par. 6, emphasis added.

31. Id.: 2017

32. See, e.g., Parker, "Surrogate Motherhood, Psychiatric Screening and Informed Consent, Baby Selling, and Public Policy," Bulletin of the American Academy of Psychiatry Law, 12 (1984): 21. 
33. 14 FLR at 2017.

34. Id. 2016 , n. 9 .

35. Id.: 203o, App. B, "Agreement,"

par. 10.

36. Id.: par. 11.

37. 13 FLR at 2012.

38. 14 FLR at 2029, App. A, par. 17.

39. Id. 2017 .

40. For a recent article summarizing such legislative proposals see Note, "Surrogate Motherhood Legislation: A Sensible Starting Point," Indiana Law Review, 20 (1987): 879, 892-94.

41. Id.: 894 .

42. See, gen., King, "Reproductive Technologies," BioLaw, 1 (1986): 113 , $115^{-17}, 122-24$.

43. See, e.g., Ga. Code $\$ 43-34-4^{2}$ (1982).

44. 14 FLR at 2028, App. A, par. 3, emphasis added.

45. Id.: 2029, App. A, par. 13.

46. 13 FLR at 2009. 0.

47. 14 FLR at 2028, App. A, par.

48. Id.

49. Id.: 2029, App. A, par. 19.

50. 13 FLR at 2019.

51. 410 U.S. 113 (1973).

52. 13 FLR at 2019 .

53. 14 FLR at 2029, App. A, par. 15.

54. One might find this analogous to the situation that led to the distinction between the duties of "treating" and "examining" physicians in some jurisdictions. See, e.g., Ahnert v. Wildman, 376 N.E.2d 1182 (Ind. App. 1978).

55. 14 FLR at 2029, App. A, par. 15.

56. See ACOG Statement of Policy, supra note 10 and accompanying text.

57. 14 FLR at 2028, App. A, par. 4 (c) (1).

58. Id.: 2009 .

59. Id.: 2028, App. A, par. 7 .

6o. Id.: 2009 .
61. New York Times, Jan. 23, 1983, sec. 1, p. 19. In fact, it was this case that may have motivated the AMA and ACOG to first address the issue.

62. See, e.g., "Model Human Reproductive Technologies and Surrogacy Act," Iowa Law Review, 72 (1987): $943,960-62$.

63. See, e.g., Draft Legislation of the National Commissioners on Uniform State Laws, "Status of Children of the New Biology," Surrogacy Provision (1987).

64. See Areen, "Handicapped Child Becomes 'Damaged Goods'," New Jersey Law Journal, 21 (Feb. 18, 1988): 25 , 26; Krimmel, "The Case Against Surrogate Parenting," Hastings Center Report, 35 (Oct. 1983).

65. New England Joumal of Medicine, 317 (Nov. 19, 1987): 1351; see also Areen, supra note 64 . 